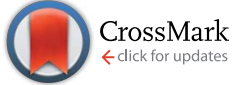

Cite this: RSC Adv., 2016, 6, 67941
Received 5th June 2016 Accepted 11th July 2016 DOI: 10.1039/c6ra14585j www.rsc.org/advances

\section{Enzymatic synthesis of 2,5-furandicarboxylic acid- based semi-aromatic polyamides: enzymatic polymerization kinetics, effect of diamine chain length and thermal properties $\uparrow$}

\author{
Yi Jiang, $\neq^{\mathrm{ab}}$ Dina Maniar, $\neq^{\mathrm{a}}$ Albert J. J. Woortman ${ }^{\mathrm{a}}$ and Katja Loos ${ }^{\star a b}$
}

2,5-Furandicarboxylic acid (FDCA)-based semi-aromatic polyamides are novel biobased alternatives to petrol-based semi-aromatic polyamides (polyphthalamides), that have a broad commercial interest as engineering thermoplastics and high performance materials. In this study, a series of FDCA-based semiaromatic polyamides is successfully produced via Novozym®435 (N435, an immobilized form of Candida antarctica lipase b (CALB))-catalyzed polycondensation of (potentially) biobased dimethyl 2,5-furandicarboxylate and aliphatic diamines differing in chain length (C4-C12), using a one-stage method at $90{ }^{\circ} \mathrm{C}$ in toluene. The obtained polyamides reach high weight-average molecular weights ranging from 15800 to $48300 \mathrm{~g} \mathrm{~mol}^{-1}$; and N435 shows the highest selectivity towards 1,8-octanediame (C8). MALDI-ToF MS analysis indicates that no byproducts are formed during the enzymatic polymerization. Study of the kinetics of the enzymatic polymerization suggests that phase separation of FDCA-based oligoamides/polyamides takes place in the early stage of polymerization, and the isolated products undergo an enzyme-catalyzed solid-state polymerization. However, the isolation yields of the purified products from the enzymatic polymerizations are less than $\sim 50 \%$ due to the production of a large amount of low molecular weight products that are washed away during the purification steps. Furthermore, the thermal properties of the enzymatic FDCA-based semi-aromatic polyamides are carefully investigated, and compared to those of the FDCA-based and petrol-based counterparts produced via conventional synthesis techniques as reported in literature.

\section{Introduction}

2,5-Furandicarboxylic acid (FDCA) can be produced by chemical or biocatalytic oxidation of 5-(hydroxymethyl)furfural (HMF) that is usually derived from various renewable carbohydrates. ${ }^{\mathbf{1 - 3}}$ Currently, FDCA is already commercially available. ${ }^{4}$ It can be expected that the price of biobased FDCA will be comparable to or even cheaper than those of the biobased and petrol-based TPA. ${ }^{5,6}$ Therefore, FDCA, currently the most promising green alternative to TPA, has great potential for industrial applications such as in the synthesis of novel aromatic polymers. These

\footnotetext{
aDepartment of Polymer Chemistry, Zernike Institute for Advanced Materials, University of Groningen, Nijenborgh 4, 9747 AG Groningen, The Netherlands. E-mail: k.u.loos@rug.nl; Tel: +31-50 3636867

${ }^{b}$ Dutch Polymer Institute (DPI), P.O. Box 902, 5600 AX Eindhoven, The Netherlands $\dagger$ Electronic supplementary information (ESI) available: Molecular weights of the crude PA8F from the enzymatic kinetics study, cumulative weight fractions of the crude PA8F determined by SEC, molecular weights and isolation yields of the purified FDCA-based semi-aromatic polyamides, SEC elution curves of the obtained FDCA-based semi-aromatic polyamides, MALDI-ToF MS spectra and DSC curves of the obtained FDCA-based semi-aromatic polyamides. See DOI: 10.1039/c6ra14585j

\$ Equal contribution.
}

polymers possess similar or even better properties than those of their petrol-based counterparts., ${ }^{2,7-9}$

Among aromatic polymers, semi-aromatic polyamides (polyphthalamides) consist of both aliphatic and aromatic monomeric units which are linked by amide bonds in the main chain. These polymers are commonly used as engineering thermoplastics and high performance materials, ${ }^{\mathbf{1 0 - 1 2}}$ owing to their good chemical/abrasion/corrosion resistance, excellent mechanical properties and many other appealing attributes. Semi-aromatic polyamides have found various applications in many fields, for example, in the automotive industry, electrical and electronics appliances, food contact materials, medical devices, photovoltaic panels and parts, and oil and gas polymers.

In general, semi-aromatic polyamides can be produced via step-growth polycondensation of aromatic diacid derivatives and aliphatic diamines at both laboratory and industrial scale, ${ }^{\mathbf{1 3}}$ usually at elevated temperatures above $200{ }^{\circ} \mathrm{C}$. However, such high temperatures may induce many undesirable sidereactions, for example, pyrolysis of aromatic diacids, $\mathrm{N}$-methylation of (poly)amides, cross-linking of polymer chains, and gel formation, as well as, self-condensation and cyclization of 
diamines. ${ }^{8,13}$ These side-reactions result in not only the formation of low molecular weight products and discoloration, but property detriments of the obtained polymeric materials.

Fortunately, the side-reactions can be greatly suppressed by using enzymatic polymerizations, due to the mild reaction conditions and the high catalytic specificity of the biocatalysts. Enzymatic polymerizations are defined as the "in vitro (in the test tubes) chemical synthesis of polymers via a nonbiosynthetic (non-metabolic) approach using an isolated enzyme as the catalyst". ${ }^{\mathbf{1 4}}$ It is an alternative and powerful pathway for the production of commodity polymers, which can compete with conventional chemical synthesis approaches and physical modifications. ${ }^{15-21}$ Enzymatic polymerizations are also capable of producing various novel polymers that are difficult to access via conventional approaches. Moreover, enzymatic polymerizations are clean processes, which can provide many advantageous sustainable aspects such as energy and material saving, non-toxic renewable enzyme catalysts, and gentle carbon footprint. ${ }^{22}$ Furthermore, by utilizing biobased monomers in enzymatic polymerizations, the energy and material consumption can be further reduced, and the generation of hazardous waste and emissions can be greatly minimized. This is essential for achieving a green polymer industry, and will eventually be beneficial for realizing and maintaining a sustainable society.

At present, 4 EC enzyme classes, including oxidoreductases (EC 1), transferases (EC 2), hydrolases (EC 3) and ligases (EC 6), are frequently used to catalyze or induce polymerizations. ${ }^{23}$ Polymer classes produced via enzymatic polymerizations include vinyl polymers, ${ }^{24,25}$ polysaccharides, ${ }^{26}$ polyesters, ${ }^{\mathbf{1 9 , 2 2}}$ polyamides, ${ }^{27-29}$ and so on. ${ }^{21,23}$

In principle, enzymes that can catalyze the formation of amide bonds are suitable biocatalysts for the synthesis of polyamides. ${ }^{27,29}$ Currently, hydrolases such as proteases, esterases (especially lipases) and other enzymes, are commonly applied for the biocatalytic synthesis of polypeptides and synthetic polyamides. Among hydrolases, Candida antarctica lipase b (CALB), especially its immobilized formulation Novozym ${ }^{\circledR} 435$ (N435), is the primary enzyme catalyst used for enzymatic polyamide synthesis, as it possesses a broad substrate specificity, high selectivity, and excellent and stable catalytic activity. Many synthetic oligoamides and polyamides were successfully synthesized via CALB-catalyzed polymerization, for example: aliphatic oligoamides, ${ }^{30}$ semi-aromatic oligoamides, ${ }^{31}$ aliphatic polyamides (nylons), ${ }^{32-36}$ silicone aromatic polyamides, ${ }^{37}$ and poly(ester amide)s. ${ }^{34,38}$

Previously, we demonstrated that CALB possesses high catalytic activity towards rigid furan monomers including dimethyl 2,5-furandicarboxylate (DMFDCA) and 2,5-bis(hydroxymethyl)furan (BHMF), ${ }^{39,40}$ and the enzymatic polymerizations yielded various FDCA-based and BHMF-based semiaromatic polyesters with high $\overline{M_{\mathrm{w}}}$ 's (weight-average molecular weights) of up to $100000 \mathrm{~g} \mathrm{~mol}^{-1}$. Recently we applied the wellestablished methodology from the enzymatic polymerization of biobased furan polyesters to prepare a FDCA-based semiaromatic polyamide, poly(octamethylene furanamide) (PA8F), starting from DMFDCA and 1,8-octanediamine (1,8-ODA) and

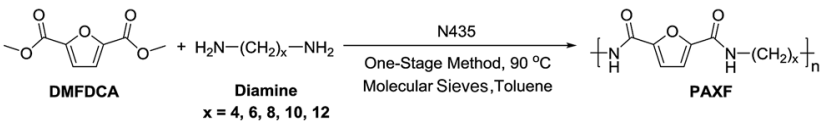

Scheme 1 Enzymatic synthesis of FDCA-based semi-aromatic polyamides (PAXF) via N435-catalyzed polycondensation of DMFDCA and aliphatic diamines at $90^{\circ} \mathrm{C}$ in toluene.

using N435 as the biocatalyst. ${ }^{41}$ High molecular weight PA8F was successfully produced via a one-stage method in toluene, with a high $\overline{M_{\mathrm{n}}}$ and $\overline{M_{\mathrm{w}}}$ of 13400 and $48300 \mathrm{~g} \mathrm{~mol}^{-1}$, respectively. On the other hand, limited studies are available on the production of FDCA-based semi-aromatic polyamides by direct polycondensation of FDCA derivatives and aliphatic diamines using conventional synthesis techniques; ${ }^{\mathbf{4 2 - 4 6}}$ and the resulting polyamides possessed relatively lower molecular weights $\left(\overline{M_{\mathrm{n}}}=\right.$ 4300-10 $000 \mathrm{~g} \mathrm{~mol}^{-1}$ ) due to the decarboxylation of FDCA and extensive occurrence of $N$-methylation of (poly)amides at elevated temperatures. ${ }^{\mathbf{8 4 5}-48}$ Therefore, enzymatic polymerizations are an appealing alternative approach for the production of FDCA-based semi-aromatic polyamides with high molecular weights. However, the isolation yields of the purified PA8F from the enzymatic polymerizations were less than $\sim 50 \%$ despite the different polymerization conditions employed, as the resulting polyamides possess a low solubility in the reaction media.

In this study, to better understand the one-stage enzymatic polymerization of FDCA-based semi-aromatic polyamides, the enzymatic polymerization kinetics is studied by NMR, SEC and MALDI-ToF MS, using DMFDCA and 1,8-ODA as model compounds. Moreover, we extend our research to synthesize a series of sustainable FDCA-based semi-aromatic polyamides by using various (potentially) biobased aliphatic diamines differing in chain length (see Scheme 1). In addition, we investigated the chemical structures, end groups, and thermal properties of the obtained polyamides. Furthermore, we compared the thermal properties of the enzymatic FDCA-based semi-aromatic polyamides to those of the FDCA-based ${ }^{\mathbf{4 2 - 4 4}}$ and TPA-based counterparts ${ }^{49-52}$ produced via conventional synthesis approaches as reported in literature.

\section{Experimental}

\section{Materials}

N435 ( $\geq 5000 \mathrm{U} \mathrm{g}^{-1}$ ), 1,4-butanediamine (1,4-BDA, 99\%), 1,6hexanediamine (1,6-HDA, 98\%), 1,8-octanediamine (1,8-ODA, 98\%), 1,10-decanediamine (1,10-DDA, 97\%), 1,12-dodecanediamine (1,12-DODA, 98\%), toluene (anhydrous, 99.8\%), formic acid (puriss, $\geq 98 \%$ ), 1,4-dioxane ( $\geq 99 \%$ ), molecular sieves (4 $\AA$ ), dimethyl sulfoxide (DMSO, HPLC grade), dimethyl sulfoxide- $d_{6}$ (DMSO- $d_{6}$ ), trifluoroacetic acid- $d_{1}$ (TFA$d_{1}$ ), and potassium trifluoroacetate (KTFA, 98\%) were purchased from Sigma-Aldrich. DMFDCA (97\%) was ordered from Fluorochem UK. 1,1,1,3,3,3-Hexafluoro-2-propanol (HFIP, $\geq 99 \%$ ) was acquired from TCI Europe. Dithranol $(\geq 98 \%)$ was purchased from Fluka. Methanol (99.8\%) was purchased from Labscan. 
The diamines, including 1,4-BDA, 1,6-HDA, 1,8-ODA, 1,10DDA, and 1,12-DODA, were purified by sublimation under reduced pressure and then stored in a desiccator. N435 was predried as reported previously. ${ }^{41,53,54}$ The molecular sieves $(4 \AA)$ were pre-activated at $200{ }^{\circ} \mathrm{C}$ in vacuo. The other chemicals were used without further purification.

\section{Procedure for N435-catalyzed polycondensation of DMFDCA and various aliphatic diamines via a one-stage method in toluene}

Pre-dried N435 (20 wt\%, in relation to the total amount of all monomers) and pre-activated 4 A molecular sieves (200 wt\%) were fed into a $25 \mathrm{~mL}$ round-bottom flask filled with nitrogen. Subsequently DMFDCA $(0.5000 \mathrm{~g}, 2.715 \mathrm{mmol})$, an aliphatic diamine (0.1917-0.4358 g, $2.715 \mathrm{mmol})$, and anhydrous toluene (500 wt\%) were introduced into the flask, thereafter the flask was sealed. The flask was then placed in an oil bath, where after the reaction mixture was magnetically stirred at $90{ }^{\circ} \mathrm{C}$ for $72 \mathrm{~h}$.

After the polymerization, toluene was evaporated by airblowing at room temperature. Then the products were dissolved by formic acid ( 15 mL). After that, N435 and molecular sieves were removed by normal filtration using filter paper. Then the N435, molecular sieves and the used filter paper were washed three times with formic acid $(\sim 10 \mathrm{~mL})$. All the solutions obtained were combined and then concentrated by a rotary evaporator at $40{ }^{\circ} \mathrm{C}$ under reduced pressure (20-40 mbar). The concentrated solution was added dropwise into an excess amount of 1,4-dioxane. The crude products were collected by centrifugation ( 30 minutes, $4500 \mathrm{rpm}, 12{ }^{\circ} \mathrm{C}$ ) and decantation at room temperature. After that, the crude products obtained were dissolved again with formic acid $(\sim 10 \mathrm{~mL})$ and then added dropwise into excess of methanol. Then the methanol solution with the precipitates was stored at $-20{ }^{\circ} \mathrm{C}$ for several hours. Subsequently, the precipitated products were collected by centrifugation (30 minutes, $4500 \mathrm{rpm}, 0{ }^{\circ} \mathrm{C}$ ) and then dried in vacuo at $40{ }^{\circ} \mathrm{C}$ for 3 days. Finally, the obtained FDCA-based semi-aromatic polyamides were stored in vacuo at room temperature prior to analysis.

Poly(butylene furanamide) (PA4F). ${ }^{1} \mathrm{H}$ NMR $(400 \mathrm{MHz}$, DMSO- $\left.d_{6}, \delta, \mathrm{ppm}\right): 8.48(1 \mathrm{H}, \mathrm{m},-\mathrm{NH}-\mathrm{CO}-$, from 1,4-BDA), 7.10 ( $2 \mathrm{H}, \mathrm{s},=C \boldsymbol{H}^{-}$, furan), $3.14\left(4 \mathrm{H}, \mathrm{m},-\mathrm{NH}-\mathrm{CH}_{2}-\right.$, from 1,4-BDA), $1.55\left(4 \mathrm{H}, \mathrm{m},-\mathrm{NH}-\mathrm{CH}_{2}-\mathrm{CH}_{2}-\right.$, from 1,4-BDA), 2.81 (t, $-\mathrm{CH}_{2}-\mathrm{NH}_{2}$, end groups from 1,4-BDA); ${ }^{13} \mathrm{C}$ NMR (75 MHz, DMSO- $d_{6}, \delta$, ppm): 157.16 (-CO-NH-, from DMFDCA), 148.14 (-NH-CO$C(\mathrm{O})=\mathrm{CH}-$, furan), 114.26 ( $=\mathrm{CH}-$, furan), 38.19 (-CO-NH$\mathrm{CH}_{2}-$, from 1,4-BDA), 26.84 (-CO-NH- $\mathrm{CH}_{2}-\mathrm{CH}_{2}-$, from 1,4BDA). Isolation yield: $0.0853 \mathrm{~g}, 7 \%$.

Polyhexamethylene furanamide) (PA6F). ${ }^{1} \mathrm{H} \mathrm{NMR}(400 \mathrm{MHz}$, DMSO- $\left.d_{6}, \delta, \mathrm{ppm}\right): 8.46$ (1H, m, -NH-CO-, from 1,6-HDA), 7.09 (2H, s, $=C \boldsymbol{H}_{-}-$, furan), $3.24\left(4 \mathrm{H}, \mathrm{m},-\mathrm{NH}-\mathrm{CH}_{2}-\right.$, from 1,6-HDA), $1.51\left(4 \mathrm{H}, \mathrm{m},-\mathrm{NH}-\mathrm{CH}_{2}-\mathrm{CH}_{2}-\right.$, from 1,6-HDA), 1.31 (4H, m, -NH$\mathrm{CH}_{2}-\mathrm{CH}_{2}-\mathrm{CH}_{2}-$, from 1,6-HDA), 3.84 (s, $-\mathrm{OCH}_{3}$, end groups from DMFDCA), $2.76\left(\mathrm{t},-\mathrm{CH}_{2}-\mathrm{NH}_{2}\right.$, end groups from 1,6-HDA); ${ }^{13} \mathrm{C}$ NMR (75 MHz, DMSO- $\left.d_{6}, \delta, \mathrm{ppm}\right): 157.33$ (-CO-NH-, from DMFDCA), 148.22 (-NH-CO-C(O)=CH-, furan), 114.44 (=CH-, furan), 38.56 (-CO-NH- $\mathrm{CH}_{2}-$, from 1,6-HDA), 29.31 (-CO-NH-
$\mathrm{CH}_{2}-\mathrm{CH}_{2}-$, from 1,6-HDA), 26.22 (-CO-NH- $\mathrm{CH}_{2}-\mathrm{CH}_{2}-\mathrm{CH}_{2}-$, from 1,6-HDA). Isolation yield: $0.2084 \mathrm{~g}, 23 \%$.

Poly(decamethylene furanamide) (PA10F). ${ }^{1} \mathrm{H}$ NMR (400 MHz, DMSO- $\left.d_{6}, \delta, \mathrm{ppm}\right): 8.44(1 \mathrm{H}, \mathrm{m},-\mathrm{NH}-\mathrm{CO}-$, from 1,10DDA), $7.08\left(2 \mathrm{H}, \mathrm{s},=C \boldsymbol{H}^{-}\right.$, furan $), 3.22\left(4 \mathrm{H}, \mathrm{m},-\mathrm{NH}-\mathrm{CH}_{2}-\right.$, from 1,10-DDA), 1.47 (4H, m, -NH- $\mathrm{CH}_{2}-\mathrm{CH}_{2}-$, from 1,10-DDA), 1.23 (12H, m, $-\mathrm{NH}-\mathrm{CH}_{2}-\mathrm{CH}_{2}-\mathrm{CH}_{2}-\mathrm{CH}_{2}-\mathrm{CH}_{2}-$, from 1,10-DDA), 3.83 ( $\mathrm{s},-\mathrm{OCH}_{3}$, end groups from DMFDCA), $2.73\left(\mathrm{t},-\mathrm{CH}_{2}-\mathrm{NH}_{2}\right.$, end groups from 1,10-DDA); ${ }^{13} \mathrm{C}$ NMR (75 MHz, DMSO- $d_{6}, \delta$, ppm): 157.07 (-CO-NH-, from DMFDCA), $148.14(-\mathrm{NH}-\mathrm{CO}-\mathrm{C}(\mathrm{O})=$ $\mathrm{CH}-$, furan), 114.18 (=CH-, furan), 38.48 (-CO-NH- $\mathrm{CH}_{2}-$, from 1,10-DDA), 29.25 (-CO-NH- $\mathrm{CH}_{2}-\mathrm{CH}_{2}-$, from 1,10-DDA), 28.91 (-CO-NH- $\mathrm{CH}_{2}-\mathrm{CH}_{2}-\mathrm{CH}_{2}-\mathrm{CH}_{2}-\mathrm{CH}_{2}-$, from 1,10-DDA), 28.73 (-CO-NH- $\mathrm{CH}_{2}-\mathrm{CH}_{2}-\mathrm{CH}_{2}-\mathrm{CH}_{2}-$, from 1,10-DDA), 26.43 (-CO$\mathrm{NH}-\mathrm{CH}_{2}-\mathrm{CH}_{2}-\mathrm{CH}_{2}-$, from 1,10-DDA). Isolation yield: $0.3150 \mathrm{~g}$, $35 \%$.

Poly(dodecamethylene furanamide) (PA12F). ${ }^{1} \mathrm{H} \quad \mathrm{NMR}$ (400 MHz, DMSO- $\left.d_{6}, \delta, \mathrm{ppm}\right): 8.42(1 \mathrm{H}, \mathrm{m},-\mathrm{NH}-\mathrm{CO}-$, from 1,12-DODA), 7.07 (2H, s, =CH-, furan), $3.21(4 \mathrm{H}, \mathrm{m},-\mathrm{NH}-$ $\mathrm{CH}_{2}-$, from 1,12-DODA), $1.46\left(4 \mathrm{H}, \mathrm{m},-\mathrm{NH}-\mathrm{CH}_{2}-\mathrm{CH}_{2}^{-}\right.$, from 1,12-DODA), 1.21 (16H, m, $-\mathrm{NH}-\mathrm{CH}_{2}-\mathrm{CH}_{2}-\mathrm{CH}_{2}-\mathrm{CH}_{2}-\mathrm{CH}_{2}-$ $\mathrm{CH}_{2}-$, from 1,12-DODA), 3.82 (s, $-\mathrm{OCH}_{3}$, end groups from DMFDCA); ${ }^{13} \mathrm{C}$ NMR (75 MHz, TFA- $\left.d_{1}, \delta, \mathrm{ppm}\right): 160.69$ (-CO$\mathrm{NH}-$, from DMFDCA), 147.70 (-NH-CO-C(O)=CH-, furan), 117.60 (=CH-, furan), 41.26 (-CO-NH- $\mathrm{CH}_{2}-$, from 1,12DODA), 29.40 (-CO-NH- $\mathrm{CH}_{2}-\mathrm{CH}_{2}-\mathrm{CH}_{2}-\mathrm{CH}_{2}-\mathrm{CH}_{2}-\mathrm{CH}_{2}-$, from 1,12-DODA), 29.06 (-CO-NH- $\mathrm{CH}_{2}-\mathrm{CH}_{2}-$, from 1,12-DODA), 28.82 (-CO-NH- $\mathrm{CH}_{2}-\mathrm{CH}_{2}-\mathrm{CH}_{2}-\mathrm{CH}_{2}-$, from 1,12-DODA), 26.71 (-CO-NH- $\mathrm{CH}_{2}-\mathrm{CH}_{2}-\mathrm{CH}_{2}-$, from 1,12-DODA). Isolation yield: $0.1473 \mathrm{~g}, 16 \%$.

FDCA-based semi-aromatic polyamides. ATR-FTIR $\left(\nu, \mathrm{cm}^{-1}\right)$ : 3290-3309 (N-H stretching vibrations); 3116-3119 $(=\mathrm{C}-\mathrm{H}$ stretching vibrations of the furan ring); 2921-2932, 2851-2865 (asymmetric and symmetric $\mathrm{C}-\mathrm{H}$ stretching vibrations); 16251646 ( $\mathrm{C}=\mathrm{O}$ stretching vibrations); 1570-1573 (aromatic $\mathrm{C}=\mathrm{C}$ bending vibrations); 1524-1531 ( $\mathrm{N}-\mathrm{H}$ bending vibrations); 1456-1472, 1435-1438 (C-H deformation and wagging vibrations); 1365-1384 (C-H rocking vibrations); 1279-1292 (C-N stretching vibrations); 1160-1166, 1012-1016 (= C-O-C= ring vibrations, furan ring); 961-968, 819-820, 757 (=C-H out-ofplane deformation vibrations, furan ring); $718\left(-\left(\mathrm{CH}_{2}\right)_{n}^{-}\right.$, rocking vibrations); 672 (C-H bending vibrations); 646-650 ( $\mathrm{N}-\mathrm{H}$ wagging vibrations).

Enzymatic polymerization kinetics study: the N435-catalyzed polycondensation of DMFDCA and 1,8-ODA via the one-stage method in toluene

${ }^{1}$ H NMR analysis. DMFDCA (0.5000 g, $\left.2.715 \mathrm{mmol}\right)$, 1,8-ODA $(0.3917 \mathrm{~g}, 2.715 \mathrm{mmol})$, pre-activated molecular sieves $(1.78 \mathrm{~g}$, $200 \mathrm{wt} \%)$, and anhydrous toluene (4.46 g, $500 \mathrm{wt} \%$ ) were added into a $25 \mathrm{~mL}$ flask with or without pre-dried N435 (0.18 g, $20 \mathrm{wt} \%$ ). The one-stage method was applied according to the same procedure as described above. At selected time intervals, about $70 \mathrm{mg}$ of solution mixture was withdrawn from the reaction. Subsequently the solution mixture was dissolved by $1 \mathrm{~g}$ of DMSO- $d_{6}$ for ${ }^{1} \mathrm{H}$ NMR analysis. 
SEC and MALDI ToF MS analysis. The one-stage method was applied for the enzymatic polycondensation of DMFDCA $(0.5000 \mathrm{~g}, 2.715 \mathrm{mmol})$ and 1,8-ODA $(0.3917 \mathrm{~g}, 2.715 \mathrm{mmol})$ in the presence of pre-dried N435 (0.18 g, $20 \mathrm{wt} \%)$ and preactivated molecular sieves (1.78 g, $200 \mathrm{wt} \%)$. A series of reactions was performed and stopped at certain polymerization times $(2,6,9,24,35$ and $72 \mathrm{~h}$, respectively). After the polymerization, formic acid $(\sim 15 \mathrm{~mL})$ was added to the reaction flask, to dissolve the resulting products. N435 and molecular sieves were then filtered off, and washed with formic acid three times. The obtained solutions were combined, and then rotary evaporated at $40{ }^{\circ} \mathrm{C}$ under reduced pressure (20-40 $\mathrm{mmHg}$ ), which afforded crude PA8F. The obtained crude PA8F was dried in vacuo at $40{ }^{\circ} \mathrm{C}$ for 3 days, and finally stored in vacuo at room temperature before SEC and MALDIToF MS analysis.

\section{Instrumental methods}

${ }^{1} \mathrm{H}$ NMR spectra were recorded on a $400 \mathrm{MHz}$ Varian VXR spectrometer and ${ }^{13} \mathrm{C}$ NMR spectra were recorded on a $300 \mathrm{MHz}$ Varian VXR spectrometer. The solvent was DMSO- $d_{6}$ or TFA- $d_{1}$. The reported chemical shifts were referenced to the resonances of the residual solvent or tetramethylsilane (TMS). The numberaverage molecular weight $\left(\overline{M_{\mathrm{n}}}\right)$ was determined by ${ }^{1} \mathrm{H}$ NMR according to literature..$^{39-41}$

Attenuated total reflection-Fourier transform infrared (ATRFTIR) spectra were recorded on a Bruker IFS88 FT-IR spectrometer, with 128 scans for each sample.

The molecular weights of the crude PA8F from the enzymatic polymerization kinetics study were measured at $80^{\circ} \mathrm{C}$ using an Agilent size exclusion chromatography (SEC) system (Agilent Technologies 1260 Infinity) from PSS (Mainz, Germany). The SEC system was equipped with three detectors (an Agilent refractive index detector G1362A 1260 RID, a PSS viscometer detector ETA-2010, and a PSS MALLS detector SLD 7000), and four columns (a PFG guard-column and three PFG SEC columns 100, 300 and $4000 \AA$ ). The detectors were kept at $45{ }^{\circ} \mathrm{C}, 60^{\circ} \mathrm{C}$ and room temperature, respectively. The eluent was DMSO (HPLC grade) with $\mathrm{LiBr}(0.05 \mathrm{M})$, with a flow rate of $0.5 \mathrm{~mL}$ $\min ^{-1} \cdot \overline{M_{\mathrm{n}}}$ and $\overline{M_{\mathrm{w}}}$ were determined by conventional calibration using a calibration curve generated by pullulan standards (from PSS, $\overline{M_{\mathrm{w}}}=342$ to $805000 \mathrm{~g} \mathrm{~mol}^{-1}$ ).

The molecular weights of the purified PA4F, PA6F, PA10F and PA12F were determined by SEC on a Viscotec GPCmax system equipped with model 302 TDA detectors, a guard column (PSS-GRAM, $10 \mu \mathrm{m}, 5 \mathrm{~cm}$ ) and two analytical columns (PSS-GRAM-1000/30 ̊, $10 \mu \mathrm{m}, 30 \mathrm{~cm}$ ). The eluent was DMF (HPLC grade) with $\operatorname{LiBr}(0.01 \mathrm{M})$, with a flow rate of $1 \mathrm{~mL} \mathrm{~min}^{-1}$. $\overline{M_{\mathrm{n}}}$ and $\overline{M_{\mathrm{w}}}$ were calculated by conventional calibration, using a calibration curve generated by polymethylmethacrylate (PMMA) standards (from PSS, $\overline{M_{\mathrm{W}}}=2460-655000 \mathrm{~g} \mathrm{~mol}^{-1}$ ).

Thermal transitions of the synthetic FDCA-based semiaromatic polyamides were characterized by a TA-Instruments Q1000 DSC (differential scanning calorimetry), with a heating and cooling rate of $10{ }^{\circ} \mathrm{C} \mathrm{min}^{-1}$. Before the standard DSC measurement, the tested polyamides were heated up to $100{ }^{\circ} \mathrm{C}$ at $10{ }^{\circ} \mathrm{C} \min ^{-1}$, kept at this temperature for $5 \mathrm{~min}$, and then cooled down to room temperature, to remove the remaining solvents and water.

Thermal stability measurements of the obtained FDCAbased semi-aromatic polyamides were performed on a PerkinElmer thermogravimetric analyzer TGA7 under nitrogen environment, with a scan rate of $10{ }^{\circ} \mathrm{C} \mathrm{min}^{-1}$. Before the standard thermal gravimetric analysis (TGA), the tested polyamides were heated up to $100{ }^{\circ} \mathrm{C}$ and then kept at this temperature for $0.5 \mathrm{~h}$, to remove the remaining solvents and water.

Matrix-assisted laser desorption/ionization-time of flight mass spectrometry (MALDI-ToF MS) measurements were performed on a Biosystems Voyager-DE PRO spectrometer in positive and linear mode. The used matrix, solvent and cationization agent were dithranol, HFIP and KTFA, respectively. At first, dithranol (20 $\left.\mathrm{mg} \mathrm{mL}^{-1}\right)$, KTFA ( $\left.5 \mathrm{mg} \mathrm{mL}^{-1}\right)$ and a polymer sample (1-2 $\left.\mathrm{mg} \mathrm{mL}^{-1}\right)$ were premixed in a ratio of $5: 1: 5$. Then the mixture was hand-spotted on a stainless steel plate and left to dry afterwards. Polyamide species having different end groups were determined by the following equation:

$$
M_{\mathrm{P}}=M_{\mathrm{EG}}+\left(n \times M_{\mathrm{RU}}\right)+M_{\mathrm{K}^{+}}
$$

where $M_{\mathrm{P}}$ is the molecular masses of a polyamide species, $M_{\mathrm{EG}}$ is the molecular mass of the end groups, $n$ is the number of the repeating units, $M_{\mathrm{RU}}$ is the molecular mass of the repeating units, and $M_{\mathrm{K}^{+}}$is the molecular mass of the potassium cation.

\section{Results and discussion}

\section{Enzymatic polymerization kinetics study}

In our previous study, we found that the one-stage enzymatic polycondensation of DMFDCA and 1,8-ODA in toluene resulted in PA8F with high molecular weights but a low isolation yield (< $50 \%$, purified products). ${ }^{41}$ To better understand the one-stage enzymatic polymerization in toluene, the enzymatic polymerization kinetics was investigated by ${ }^{1} \mathrm{H}$ NMR, SEC and MALDI-ToF MS (see Fig. 1-5, and Tables S1 and S2 in the $\mathrm{ESI} \dagger$ ).

We noticed that FDCA-based semi-aromatic oligoamides were already produced within 30 minutes of reaction time, as proven by the appearance of a new signal at $3.83 \mathrm{ppm}$ that is ascribed to the methoxyl groups of oligoamides (see Fig. 1). Moreover, the proton signal assigned to the methoxyl groups of DMFDCA disappeared completely after $2 \mathrm{~h}$ oligomerization, indicating that all DMFDCA monomer was converted to oligoamides. This agreed well with our previous result, which proved that $2 \mathrm{~h}$ oligomerization is sufficient for the enzymatic polycondensation of aliphatic polyesters. ${ }^{54}$

However, when the polymerization time was extended from 3 to $9 \mathrm{~h}$, the relative intensity of the peak ascribed to the methoxyl groups of the resulting oligoamides/polyamides decreased significantly. This is due to the precipitation of the resulting products because of their low solubility. Moreover, no resonances can be assigned to the protons of the FDCA-based oligoamides/polyamides after $\sim 22 \mathrm{~h}$ reaction. This suggested 


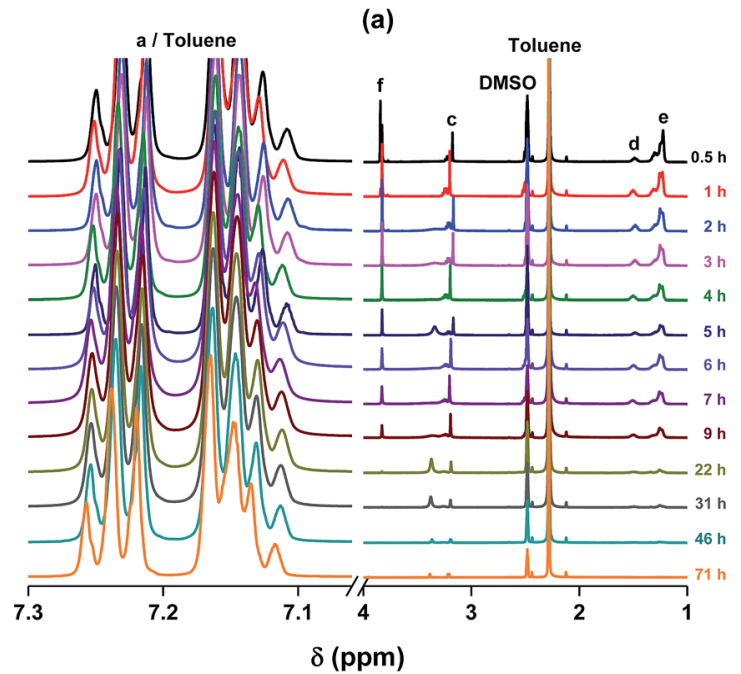

(b)

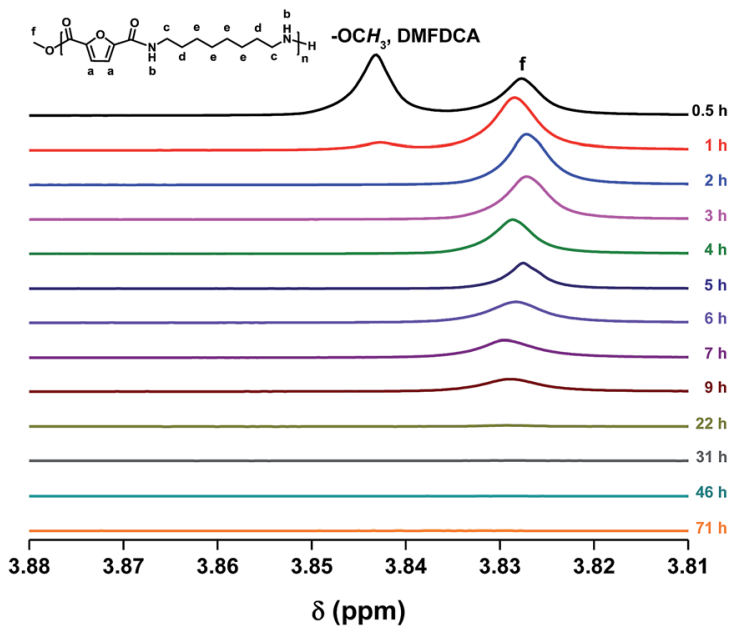

Fig. $1{ }^{1} \mathrm{H}$ NMR spectra of the solution mixture from the N435-catalyzed polycondensation of DMFDCA and $1,8-$ ODA at $90^{\circ} \mathrm{C}$ in toluene.

that no resulting products were identified in the reaction mixture, as they were totally isolated from the reaction media due to the precipitation.

In contrast to this, the monomer DMFDCA and the resulting FDCA-based oligoamides/polyamides were clearly detected from the control reaction in the absence of N435 after $0.5-71 \mathrm{~h}$ reaction (see Fig. 2). Meanwhile, more oligoamides/polyamides were prepared at a longer polymerization time, as the relative intensity of the peak ascribed to the monomer DMFDCA decreases gradually with the increase of polymerization time. This indicated that the condensation between DMFDCA and 1,8-ODA can occur in the absence of catalysts, but the reaction rate is rather low. In other words, from Fig. 1 and 2 we can draw the conclusion that the polycondensation is indeed catalyzed by $\mathrm{N} 435$, which resulted in high molecular weight PA8F as reported in our previous study. ${ }^{\mathbf{4 1}}$

The enzymatic polymerization kinetics was also investigated by SEC (Fig. 3 and 4 and Tables S1 and S2 $\dagger$ ). Fig. 3 depicts the SEC elution curves of the crude PA8F from the enzymatic (a)

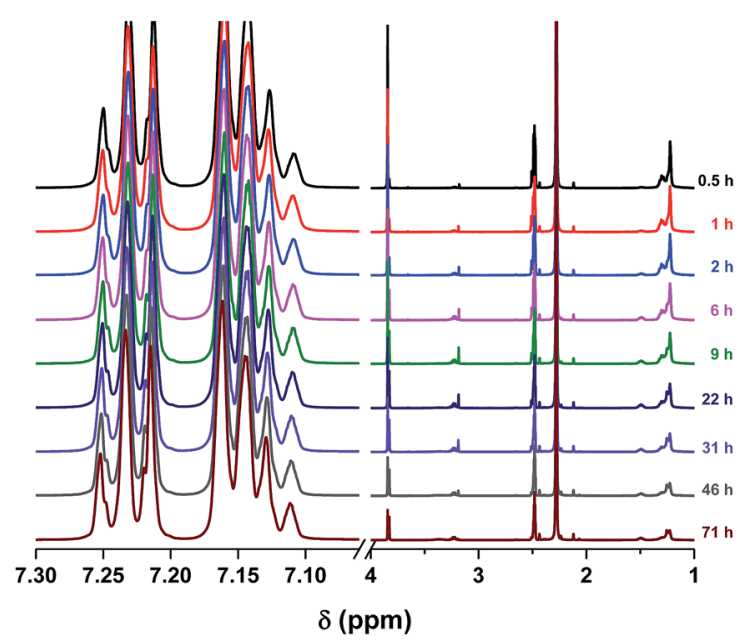

(b)

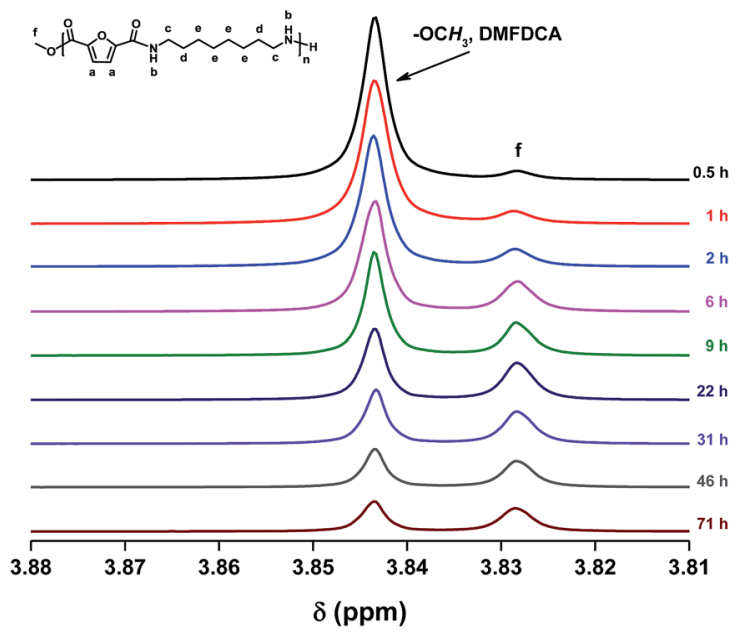

Fig. $2{ }^{1} \mathrm{H}$ NMR spectra of the solution mixture from the control reaction of DMFDCA and $1,8-\mathrm{ODA}$ at $90^{\circ} \mathrm{C}$ in toluene in the absence of $\mathrm{N} 435$.

kinetics study and a plot of degrees of polymerization $(\overline{\mathrm{DP}})$ as a function of the polymerization time. When the polymerization time was extended from 2 to $24 \mathrm{~h}$, the major retention volume of the obtained crude PA8F shifted significantly to a lower value (Fig. 3a), indicating the formation of higher molecular weight products at a longer polymerization time. As shown in Fig. $3 \mathrm{~b}$ and Table $\mathrm{S} 1, \dagger$ the corresponding number-average degree of polymerization $\left(\overline{\mathrm{DP}_{\mathrm{n}}}\right)$, weight-average degree of polymerization $\left(\overline{\mathrm{DP}_{\mathrm{w}}}\right)$, and peak degree of polymerization $\left(\overline{\mathrm{DP}_{\mathrm{p}}}\right.$, the major retention volume) increased significantly, from 4,5 and 4 to 14 , 48 and 42, respectively. Upon further increasing the polymerization time from 24 to $72 \mathrm{~h}$, the $\overline{\mathrm{DP}_{\mathrm{n}}}$ and $\overline{\mathrm{DP}_{\mathrm{p}}}$ slightly increased, from 14 and 42 to 15 and 50, respectively. On the contrary, the $\overline{\mathrm{DP}_{\mathrm{w}}}$ showed a significant increase from 48 to 81 , even though all the resulting PA8F was phase separated from the reaction after $\sim 22 \mathrm{~h}$ reaction as indicated by the NMR study discussed above. This is consistent with the MALDI-ToF MS results which also confirmed that the enzymatic polymerization at longer reaction times resulted in longer chain PA8F (Fig. 5). The chain 
(a)

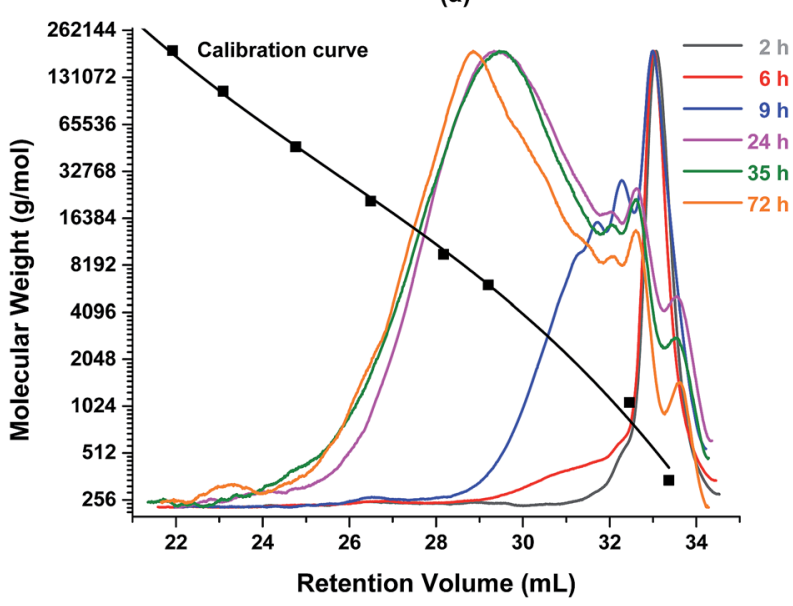

(b)

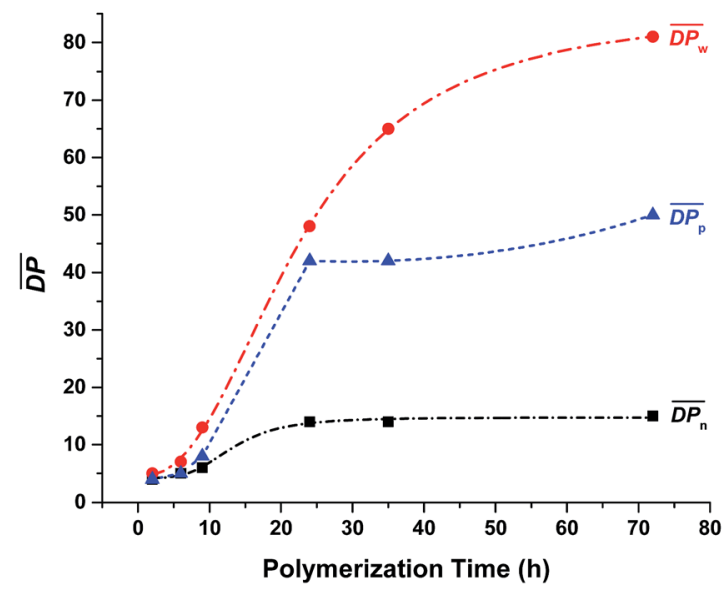

Fig. 3 (a) SEC elution curves of the obtained crude PA8F from the N435-catalyzed polycondensation of DMFDCA and 1,8-ODA in toluene at different polymerization times; and (b) $\overline{\mathrm{DP}_{n}}, \overline{\mathrm{DP}_{\mathrm{w}}}$ and $\overline{\mathrm{DP}_{\mathrm{p}}}$ of the crude PA8F determined by SEC as a function of the polymerization

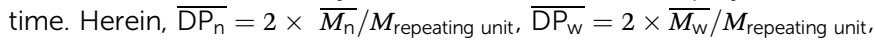
$\overline{\mathrm{DP}_{\mathrm{p}}}=2 \times \overline{M_{\mathrm{p}}} / M_{\text {repeating unit, }}$ where $M_{\text {repeating unit }}$ is the molecular mass of the repeating units.

growth of the isolated products after $\sim 22 \mathrm{~h}$ reaction could be explained by the N435-catalyzed solid-state polymerization, as postulated in our previous study. ${ }^{\mathbf{4 1}}$

However, only a small amount of high molecular weight PA8F was produced via the solid-state polymerization, suggesting that the efficiency of the enzymatic solid-state polymerization was quite low. As the cumulative weight fractions determined by SEC shown (see Fig. 4 and Table S2†), the enzymatic solid-state polymerization afforded $\sim 3-4 \%$ of additional PA8F with $\overline{\mathrm{DP}}$ of 42-509 (5500-67 $\left.200 \mathrm{~g} \mathrm{~mol}^{-1}\right)$ and $~ 5 \%$ of extra PA8F with higher $\overline{\mathrm{DP}}$ of 509-1350 (67 200-178 $400 \mathrm{~g}$ $\mathrm{mol}^{-1}$ ), when the polymerization time was increased from 24 to $72 \mathrm{~h}$.

We also found that a large proportion of short chain PA8F was produced via the enzymatic polymerization. As shown in Fig. 4 and Table $S 2, \dagger$ after $72 \mathrm{~h}$ polymerization, $\sim 27 \%$ of the obtained crude PA8F possessed a low $\overline{\mathrm{DP}}$ of less than $16(<2100 \mathrm{~g}$

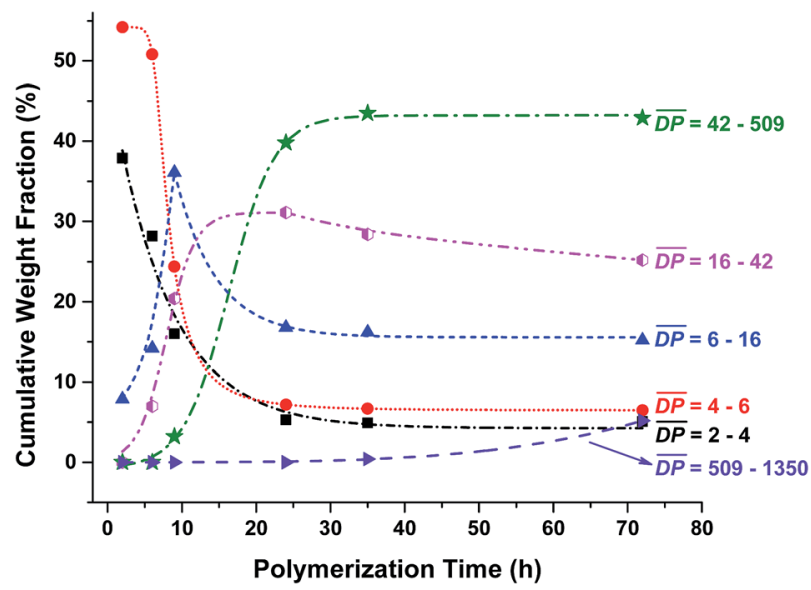

Fig. 4 Evolution of the cumulative weight fractions of the obtained crude PA8F with different degrees of polymerization $(\overline{\mathrm{DP}})$ as a function of polymerization time. The crude PA8F was obtained from the enzymatic kinetics study; and $\overline{\mathrm{DP}}$ and cumulative weight fractions were determined by SEC.

$\left.\mathrm{mol}^{-1}\right)$; and the amount of PA8F with $\overline{\mathrm{DP}}$ of less than $42(<5500 \mathrm{~g}$ $\mathrm{mol}^{-1}$ ) reached $\sim 52 \%$. The short chain PA8F possesses a high solubility in the used precipitants (1,4-dioxane and methanol) and therefore, they were washed away during the purification steps. Thus, only less than $\sim 50 \%$ of the products were collected after purification, and this could be improved by choosing other proper precipitants.

In summary, the enzymatic polymerization kinetics study indicated that phase separation of FDCA-based oligoamides/ polyamides occurred in the early stage of polymerization, and that the resulting PA8F has undergone a subsequent enzymatic solid-state polymerization. However, due to the phase separation and the low efficiency of the enzymatic solidstate polymerization, a large proportion of short chain PA8F was produced, which led to the low yields of the purified products.

\section{N435-catalyzed polycondensation of DMFDCA and various aliphatic diamines via a one-stage method in toluene}

A series of FDCA-based semi-aromatic polyamides including PA4F, PA6F, PA8F, PA10F and PA12F was successfully synthesized via a one-stage enzymatic polycondensation in toluene (see Scheme 1). The diamines used were (potentially) biobased 1,4-butanediamine (1,4-BDA), 1,6-hexanediamine (1,6-HDA), 1,8-octanediamine (1,8-ODA), 1,10-decanediamine (1,10-DDA), and 1,12-dodecanediamine (1,12-DODA). The number of methylene units in the diamine segments is 4, 6, 8, 10 and 12 , respectively, which defines the chain length $(x)$ of the tested aliphatic diamines.

The chemical structures of the obtained FDCA-based semiaromatic polyamides are confirmed by NMR and ATR-FTIR (see Fig. 6 and 7). The detailed NMR and IR assignments are described in the Experimental section and in our previous report. ${ }^{41}$ 
(a)

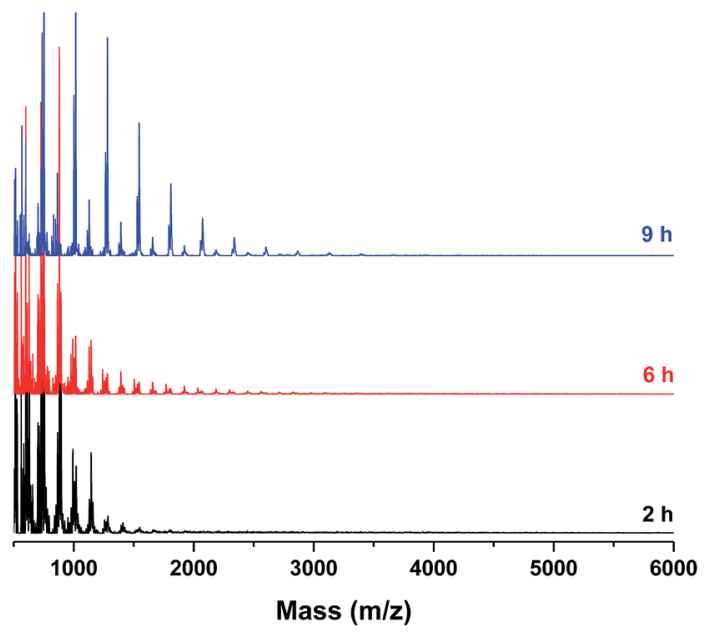

(b)

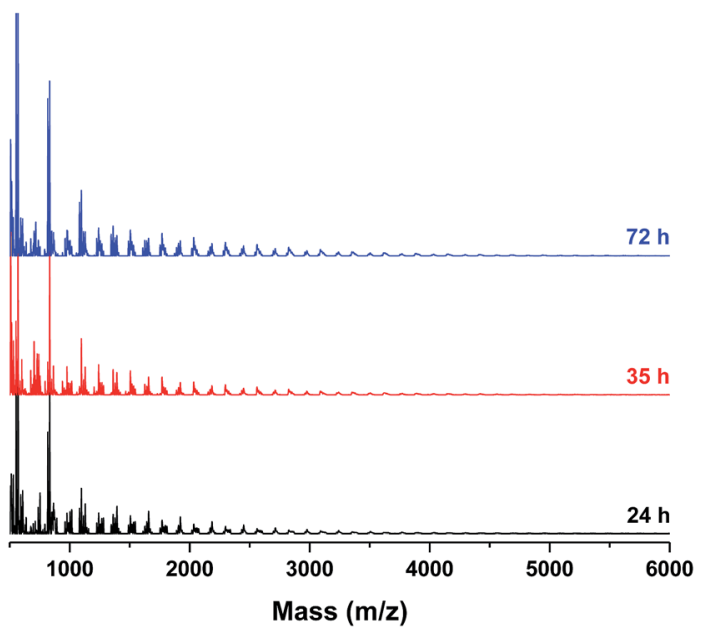

Fig. 5 MALDI-ToF MS spectra of the obtained crude PA8F from the enzymatic kinetics study at different polymerization times.

\section{Effect of diamine chain length on enzymatic polymerization}

The molecular weights of the obtained FDCA-based semiaromatic polyamides were determined by NMR and SEC, as summarized in Tables 1 and S3 in the ESI. $\dagger$ The SEC retention curves are illustrated in Fig. S1 (see ESI $\dagger$ ) and in our previous report. $^{41}$

Fig. 8 depicts $\overline{\mathrm{DP}_{\mathrm{w}}}$ and yield of the purified FDCA-based semi-aromatic polyamides against the chain length of the tested aliphatic diamines. The same trend with respect to the diamine chain length is observed: the $\overline{\mathrm{DP}_{\mathrm{w}}}$ and yield of the purified products increased significantly with increasing the diamine chain length from 4 to 8 ; however, by further increasing the diamine chain length from 8 to 12, the enzymatic polymerization resulted in a lower $\overline{\mathrm{DP}_{\mathrm{w}}}$ and a reduction in yield of the purified products. This indicated that N435 shows the highest selectivity towards 1,8-ODA, which is in good agreement with the previous study on the enzymatic polymerization of aliphatic polyamides as reported by our laboratory. ${ }^{30}$
The enzymatic polymerization with 1,4-BDA having the shortest chain length amongst the tested aliphatic diamines resulted in PA4F with the lowest isolation yield. This could be mainly attributed to two reasons. First, 1,4-BDA is not favored by CALB due to its short chain length while second PA4F possesses the lowest solubility among the FDCA-based semiaromatic polyamides.

Moreover, the isolation yield of the purified products from the enzymatic polymerizations was less than $\sim 50 \%$. This can be explained by the production of a large proportion of low molecular weight oligoamides due to the occurrence of phase separation and the low efficiency of the enzyme-catalyzed solidstate polymerization as discussed before. Noteworthy is that the enzymatic polymerization can be significantly improved by using a two-stage method in diphenyl ether as reported in our previous study. ${ }^{41}$ We found that the two-stage enzymatic polymerization in diphenyl ether can afford high molecular weight PA8F with a higher isolation yield of $\sim 70 \%$.

\section{Enzymatic approach versus conventional synthesis techniques}

Previously, FDCA-based semi-aromatic polyamides were produced via conventional synthesis techniques, including melt, solution and interfacial polymerization, as reported in literature. ${ }^{\mathbf{4 2 - 4 4}}$ Due to the low solubility of the resulting polyamides and the extensive occurrence of side-reactions at elevated temperatures such as the decarboxylation of FDCA and $N$-methylation of (poly)amides, ${ }^{8}$ FDCA-based semi-aromatic polyamides with relatively low molecular weights were obtained, with $\overline{M_{\mathrm{n}}}$ and $\overline{M_{\mathrm{w}}}$ ranged from 4000 to 10000 and 11100 to $18800 \mathrm{~g} \mathrm{~mol}^{-1}$, respectively (Table 1 ). However, in our study, even under a mild reaction temperature, the enzymatic polymerization generally resulted in a higher $\overline{M_{\mathrm{n}}}$ and $\overline{M_{\mathrm{w}}}$ of around 9500-13 400 and 15 800-48300 g mol $\mathrm{g}^{-1}$, respectively. As confirmed by MALDI-ToF MS analysis (see below), no sideproducts were formed during the enzymatic polymerization,

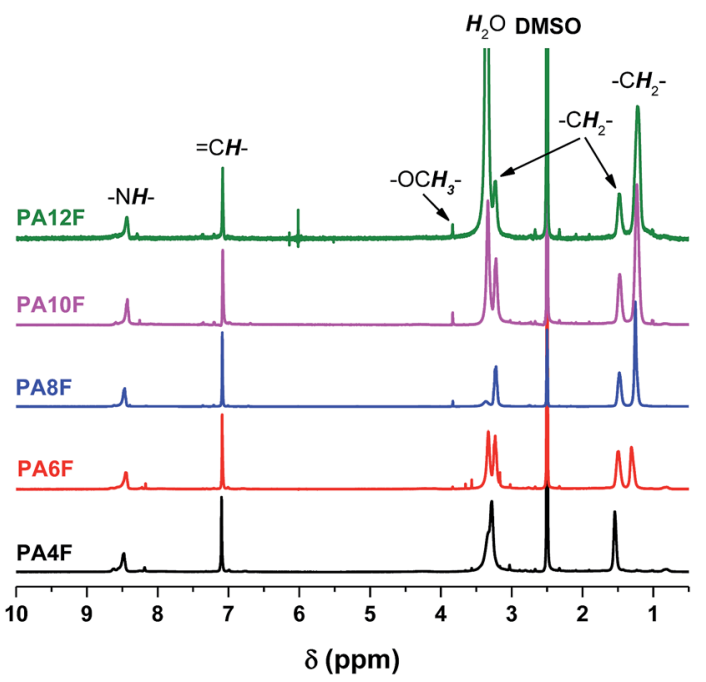

Fig. $6{ }^{1} \mathrm{H}$ NMR spectra of FDCA-based semi-aromatic polyamides. 


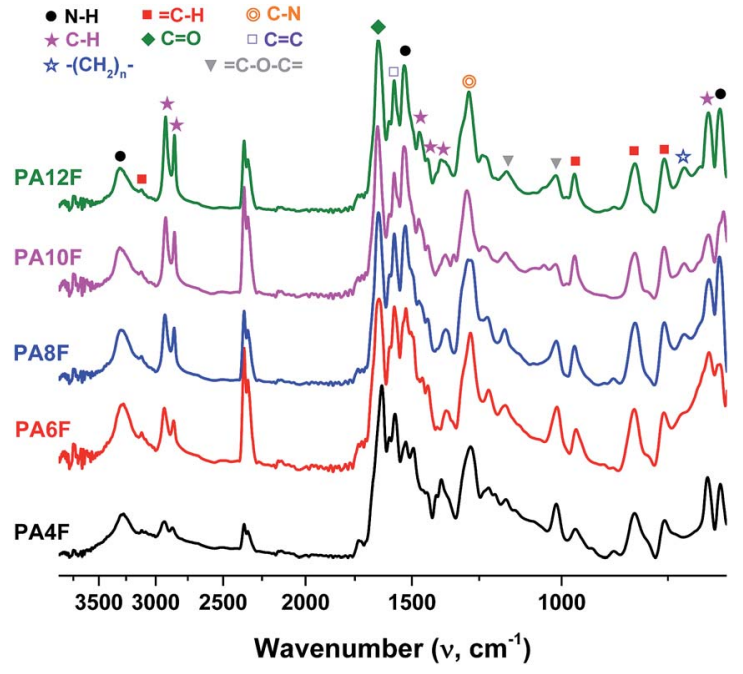

Fig. 7 ATR-FTIR spectra of FDCA-based semi-aromatic polyamides.

which could have indicated the decarboxylation of DMFDCA and $N$-methylation of (poly)amides. This suggested that such side-reactions were greatly prevented by using N435 as the catalyst. To conclude, we have proven that enzymatic catalysis is a powerful approach towards the synthesis of sustainable FDCAbased semi-aromatic polyamides.

It should be noted that the reaction time used for the enzymatic polymerization was longer than that applied for the conventional synthesis approaches. However, as indicated by the enzymatic kinetics study, the enzymatic polymerization time could be shortened from 72 to $\sim 24 \mathrm{~h}$. In this case the enzymatic polymerization could result in FDCA-based semiaromatic polyamides with similar $\overline{M_{\mathrm{n}}}$ values. Therefore, the enzymatic polymerization is comparable to the conventional approaches with respect to the reaction time and the resulting molecular weights. Furthermore, the enzymatic polymerization is an energy saving process as the reaction temperature is mild; and no harmful residuals are remained in the resulting polyamides by using enzymes as catalysts. Besides, the immobilized enzyme catalysts can be recycled and reused for many cycles. ${ }^{55}$

\section{MALDI-ToF MS analysis}

The end groups of the obtained FDCA-based semi-aromatic polyamides were determined by MALDI-ToF MS. Eight polyamide species with different abundance were identified (see Table 2, Fig. 9, and S2-S5 in the ESI $\dagger$ ), which is in good agreement with our previous study. ${ }^{41}$ The identified polyamide species were terminated with ester/amine, ester/ester, amine/ amine, acid/amine, ester/acid, acid/acid, and ester/amide, as well as, without end groups (cyclic polyamides).

The acid end group was produced by a N435-catalyzed hydrolysis of esters during the polymerization; ${ }^{31,41}$ and the formation of the amide end group was due to the reaction between the amine groups and formic acid at the purification step. $^{31,41,56}$

\section{Thermal properties of the obtained FDCA-based semi- aromatic polyamides}

The thermal stability of the obtained FDCA-based semiaromatic polyamides was characterized by TGA. All tested polyamides showed a decomposition temperature at $5 \%$ weight loss $\left(T_{\mathrm{d}-5 \%}\right)$ and a temperature at the maximum rate of decomposition $\left(T_{\mathrm{d}-\max }\right)$ at around $257-378$ and $443-466{ }^{\circ} \mathrm{C}$, respectively (see Table 1 and Fig. 10). We also found that the obtained PA4F is less thermally stable compared to the other tested polymers, which is probably due to its relatively low $\overline{M_{\mathrm{w}}}$. Moreover, considering their high $T_{\mathrm{d}-\max }$, all the tested FDCAbased semi-aromatic polyamides possess a very broad processing window.

The thermal transitions of the obtained FDCA-based semiaromatic polyamides were analyzed by DSC (see Table 1, Fig. 11, and S6-S9 in the ESI†). Broad melting peaks ranging from 125 to $162{ }^{\circ} \mathrm{C}$ were observed in the first DSC heating curves, except for PA4F which possesses a high $T_{\mathrm{m}}$ above the tested temperature $\left(200{ }^{\circ} \mathrm{C}\right)$ due to its high chain rigidity. As reported by Heertjes and Kok, ${ }^{43}$ the $T_{\mathrm{m}}$ of PA4F with a $\overline{M_{\mathrm{n}}}$ of around $6000-10000 \mathrm{~g} \mathrm{~mol}^{-1}$ is $250{ }^{\circ} \mathrm{C}$. Moreover, the tested FDCA-based semi-aromatic polyamides possessed a lower $T_{\mathrm{m}}$ when the chain length of aliphatic diamine units increased (Fig. 12a). A similar trend was also observed for the FDCA-based semi-aromatic polyesters ${ }^{40}$ and TPA-based semi-aromatic polyamides. ${ }^{50,52}$ In this study, the decrease of $T_{\mathrm{m}}$ with increasing of the aliphatic diamine chain length can be explained by two facts. The increase of the aliphatic diamine chain length results in an increase in the chain flexibility and a decrease in the density of hydrogen bonds and $\pi-\pi$ stackings.

The enthalpy of fusion $\left(\Delta H_{\mathrm{m}}\right)$ of the tested FDCA-based semiaromatic polyamides increased significantly from 6 to $\sim 40 \mathrm{~J} \mathrm{~g}^{-1}$ when the chain length of aliphatic diamine units was increased from 6 to 10 and 12 (see Table 1). This may suggest that the FDCA-based semi-aromatic polyamides with longer aliphatic diamine units possess a higher crystallization ability because of the higher chain flexibility.

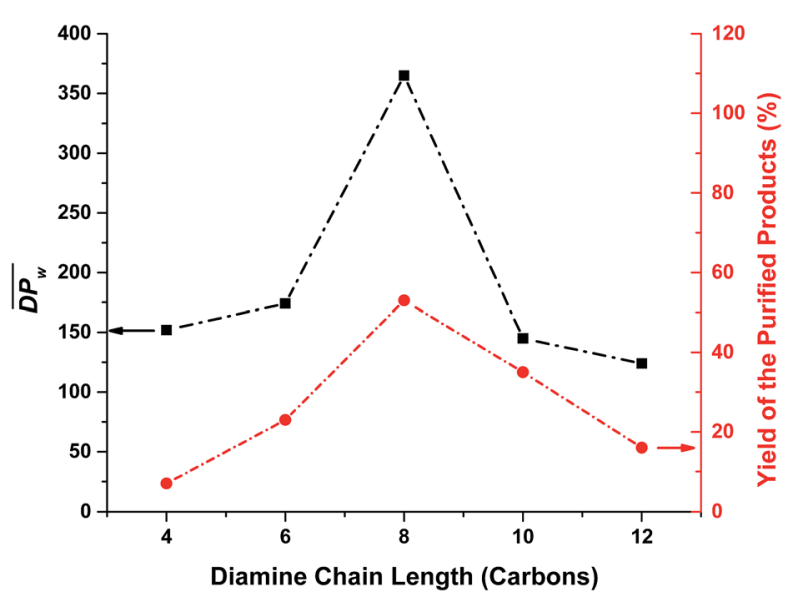

Fig. $8 \overline{\mathrm{DP}_{\mathrm{w}}}$ and isolation yield of the purified FDCA-based semiaromatic polyamides from the enzymatic polymerization against the diamine chain length. 
Table 1 Molecular weights and thermal properties of the FDCA-based and TPA-based semi-aromatic polyamides

\begin{tabular}{|c|c|c|c|c|c|c|c|}
\hline Polymer & Synthesis approach & $\overline{M_{\mathrm{n}}}\left(\mathrm{g} \mathrm{mol}^{-1}\right)$ & $\overline{M_{\mathrm{w}}}\left(\mathrm{g} \mathrm{mol}^{-1}\right)$ & $T_{\mathrm{m}}\left({ }^{\circ} \mathrm{C}\right)$ & $\Delta H_{\mathrm{m}}\left(\mathrm{J} \mathrm{g}^{-1}\right)$ & $T_{\mathrm{g}}\left({ }^{\circ} \mathrm{C}\right)$ & $T_{\mathrm{d}}\left({ }^{\circ} \mathrm{C}\right)$ \\
\hline PA4F & Enzymatic & $12300^{a}$ & 15800 & $-^{f}$ & $-^{f}$ & $119^{g}$ & $257^{k} ; 443^{l}$ \\
\hline PA6F & Enzymatic & $13400^{a}$ & 20600 & $162^{g}$ & $6^{g}$ & $119^{g}$ & $322^{k} ; 460^{l}$ \\
\hline PA10F & Enzymatic & $13400^{a}$ & 21200 & $135^{g}$ & $47^{g}$ & $98^{g}$ & $366^{k} ; 463^{l}$ \\
\hline PA12F & Enzymatic & $9500^{a}$ & 19900 & $125138^{g}$ & $43^{g}$ & $82^{g}$ & $321^{k} ; 466^{l}$ \\
\hline PA4F $F^{43}$ & Interfacial & $6000-10000^{c}$ & $-^{e}$ & $250^{h}$ & $-^{e}$ & $-^{e}$ & $-^{e}$ \\
\hline PA8F $^{44}$ & Melt & $4300^{d}$ & 11100 & $-^{e}$ & $-^{e}$ & $83^{j}$ & $350-450^{h}$ \\
\hline PA8F ${ }^{43}$ & Melt & $6000-10000^{c}$ & $\underline{-}^{e}$ & $125^{h}$ & $-^{e}$ & $-^{e}$ & $-^{e}$ \\
\hline PA10F ${ }^{44}$ & Melt & $5300^{d}$ & 12700 & $-^{e}$ & $-^{e}$ & $71^{j}$ & $350-450^{h}$ \\
\hline $\mathrm{PA}_{10 F^{42}}$ & Interfacial & $\leq 8800(\overline{\mathrm{DP}} \leq 30)^{h}$ & $-^{e}$ & $130^{h}$ & $-^{e}$ & - & - \\
\hline PA12F $F^{44}$ & Melt & $7000^{d}$ & 18800 & $-^{e}$ & $-^{e}$ & $68^{j}$ & $350-450^{h}$ \\
\hline $\mathrm{PA}_{4} \mathrm{~T}^{49}$ & Interfacial & $-^{e}$ & $-^{e}$ & $436^{i}$ & $-^{e}$ & $-^{e}$ & $-^{e}$ \\
\hline PA8T ${ }^{51}$ & $-^{e}$ & $-^{e}$ & $-^{e}$ & $338^{g}$ & $-^{e}$ & $-^{e}$ & $402^{m}$ \\
\hline $\mathrm{PA}_{10 \mathrm{~T}^{52}}$ & Solid-state & $-^{e}$ & $-^{e}$ & $290^{g}$ & $-^{e}$ & $113^{g}$ & $\sim 426^{m} ; \sim 482^{n}$ \\
\hline PA12T ${ }^{52}$ & Solid-state & $-^{e}$ & $-^{e}$ & $270^{g}$ & $-^{e}$ & $96^{g}$ & $\sim 426^{m} ; \sim 482^{n}$ \\
\hline
\end{tabular}

$a \overline{M_{\mathrm{n}}}$ (number-average molecular weight) and $\overline{M_{\mathrm{w}}}$ (weight-average molecular weight) were determined by SEC using DMF/LiBr as the eluent. ${ }^{b} \overline{M_{\mathrm{n}}}$ and $\overline{M_{\mathrm{w}}}$ were determined by SEC using $\mathrm{DMSO} / \mathrm{LiBr}$ as the eluent. ${ }^{c} \overline{M_{\mathrm{n}}}$ was determined by end group titration. ${ }^{d} \overline{M_{\mathrm{n}}}$ and $\overline{M_{\mathrm{w}}}$ were determined by SEC using HFIP as the eluent. ${ }^{e}$ Not mentioned in the literature. ${ }^{f}$ Not detected at the tested time temperature scales. ${ }^{g} T_{\mathrm{m}}$ (melting temperature) and $\Delta H_{\mathrm{m}}$ (enthalpy of fusion) were determined by DSC (first heating scan), with a heating rate of $10^{\circ} \mathrm{C}$ min ${ }^{-1}$; the $T_{\mathrm{g}}$ (glass transition temperature) was determined by DSC (second heating scan), with a heating rate of $10^{\circ} \mathrm{C} \min ^{-1}$. ${ }^{h}$ The test method wass not mentioned in the literature. ${ }^{i} T_{\mathrm{m}}$ and $T_{\mathrm{g}}$ were determined by DTA (differential thermal analysis) at a heating rate of $20{ }^{\circ} \mathrm{C}$ min ${ }^{-1}$. ${ }^{j} T_{\mathrm{g}}$ was determined by DSC at a heating rate of $5{ }^{\circ} \mathrm{C} \mathrm{min}^{-1} .{ }^{k}$ Decomposition temperature at $5 \%$ weight loss $\left(T_{\mathrm{d}-5 \%}\right) .{ }^{l}$ Temperature at the maximum rate of decomposition $\left(T_{\mathrm{d}-\mathrm{max}}\right) \cdot{ }^{m}$ Initial degradation temperature. ${ }^{n}$ Framework collapses temperature; $T_{\mathrm{d}}=$ decomposition temperature.

No crystallization was observed in the DSC cooling curves of all tested polyamides, and no melting peak appeared in the second heating curves (see Fig. 11, and S6-S9 in the ESI $\dagger$ ).
This indicated that all synthesized FDCA-based semiaromatic polyamides cannot crystallize in bulk at the tested

Table 2 MALDI-ToF MS analysis: end groups of the obtained FDCA-based semi-aromatic polyamides

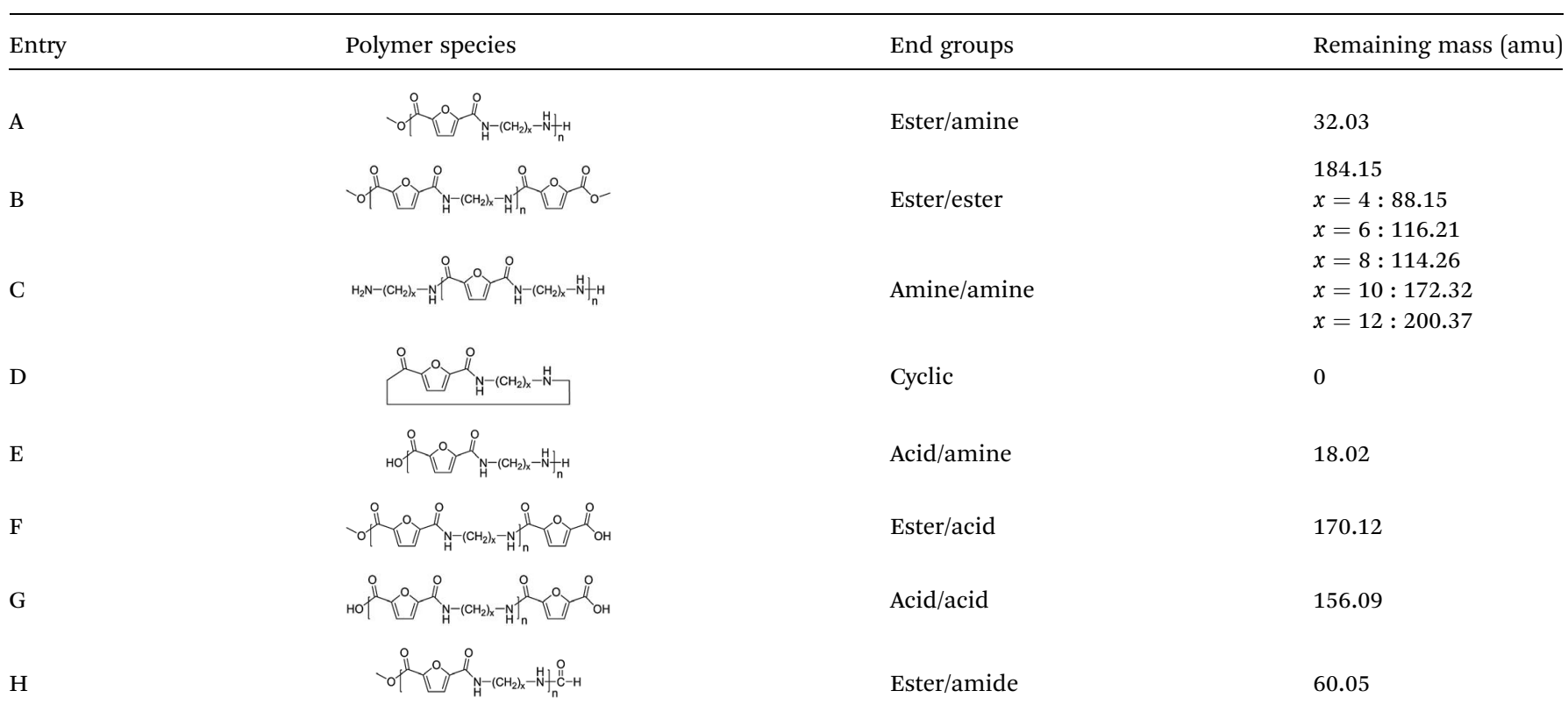




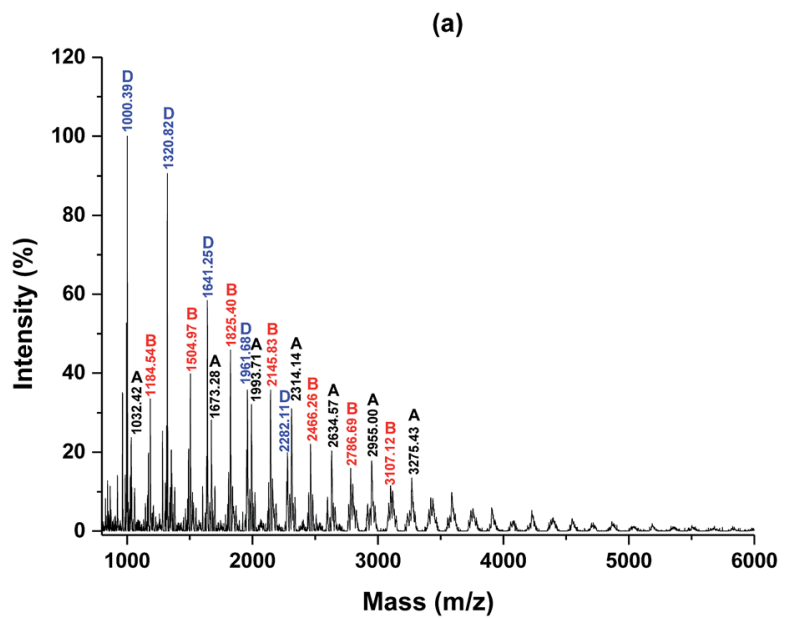

(b)

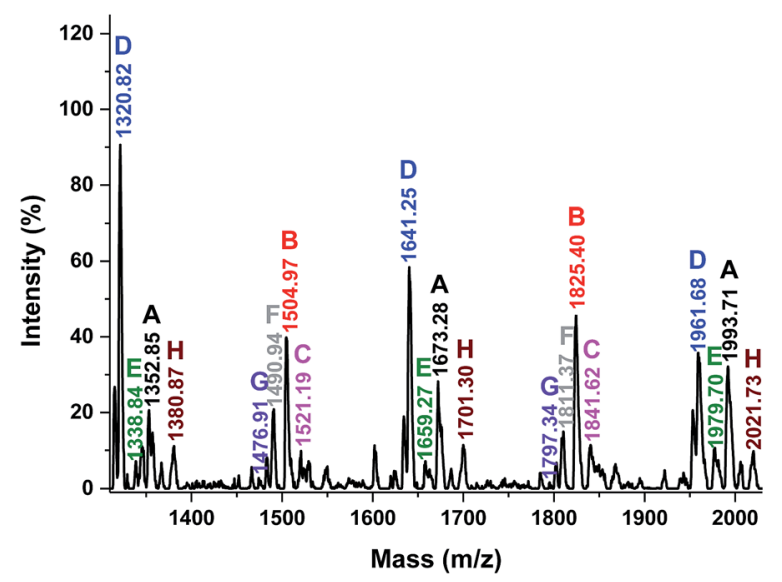

Fig. 9 MALDI-ToF MS spectrum of the obtained PA12F with detailed peak interpretation.

conditions, which can be explained by their slow crystallization rate. ${ }^{41}$

The $T_{\mathrm{g}}$ of the obtained FDCA-based semi-aromatic polyamides decreased gradually from 119 to $82{ }^{\circ} \mathrm{C}$ when the chain length of aliphatic diamine units was increased from 4 to 12 (Fig. 12b), which can be explained by the same line of reasoning as discussed above for $T_{\mathrm{m}}$. Again this agreed well with the previous studies reported. ${ }^{40,52,57}$ It was found that the FDCAbased semi-aromatic polyesters and TPA-based semi-aromatic polyamides showed a continuous reduction in $T_{\mathrm{g}}$ with an increase of the chain length of aliphatic diol/diamine units.

\section{Comparison of the thermal properties: enzymatic FDCA-based} semi-aromatic polyamides versus FDCA-based and TPA-based counterparts produced via conventional synthesis techniques

The FDCA-based semi-aromatic polyamides produced from the enzymatic polymerizations possess similar thermal stability compared to the FDCA-based and TPA-based counterparts obtained via conventional approaches (see Table 1).

Moreover, $T_{\mathrm{m}}$ and $T_{\mathrm{g}}$ of the enzymatic FDCA-based semiaromatic polyamides are generally higher than those of the counterparts synthesized via the conventional synthesis

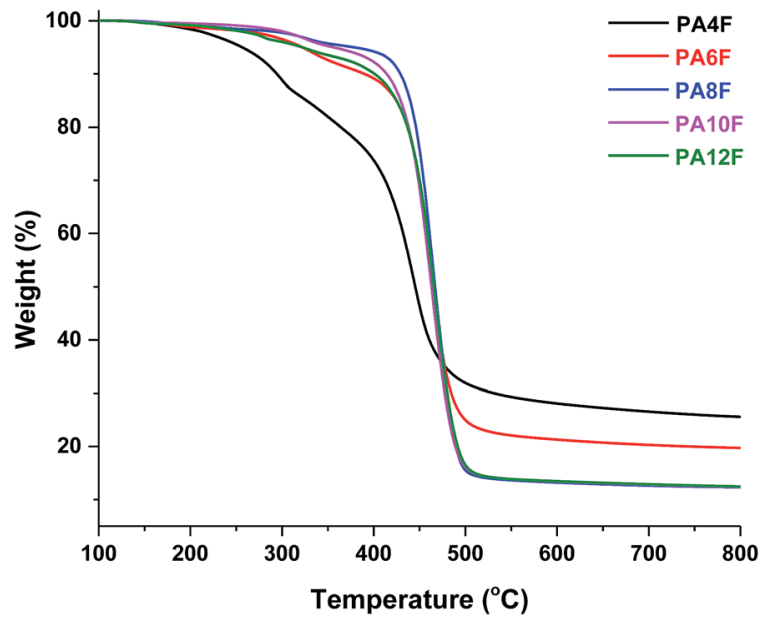

Fig. 10 TGA curves of the obtained FDCA-based semi-aromatic polyamides produced via a one-stage enzymatic polymerization in toluene at $90^{\circ} \mathrm{C}$.

techniques (Fig. 12). This could be rationalized by the higher molecular weights of the enzymatic FDCA-based polyamides.

Furthermore, $T_{\mathrm{g}}$ of the enzymatic FDCA-based semiaromatic polyamides is a bit lower than that of the TPAbased counterparts. This could be attributed to the lower molecular weights of the FDCA-based semi-aromatic polyamides, and the lower density of intermolecular hydrogen bonds. The latter is due to the formation of additional interactions between amide groups and oxygen heteroatoms of the furan ring as reported in literature. ${ }^{58}$ Given the fact that the difference in $T_{\mathrm{g}}$ is quite small $\left(6-15{ }^{\circ} \mathrm{C}\right)$, we can draw the conclusion that the FDCA-based and TPA-based semi-aromatic polyamides possess a comparable $T_{\mathrm{g}}$.

However, the TPA-based semi-aromatic polyamides possess a much higher $T_{\mathrm{m}}$, which is more than $130^{\circ} \mathrm{C}$ higher than those of the FDCA-based counterparts. This is attributed to the

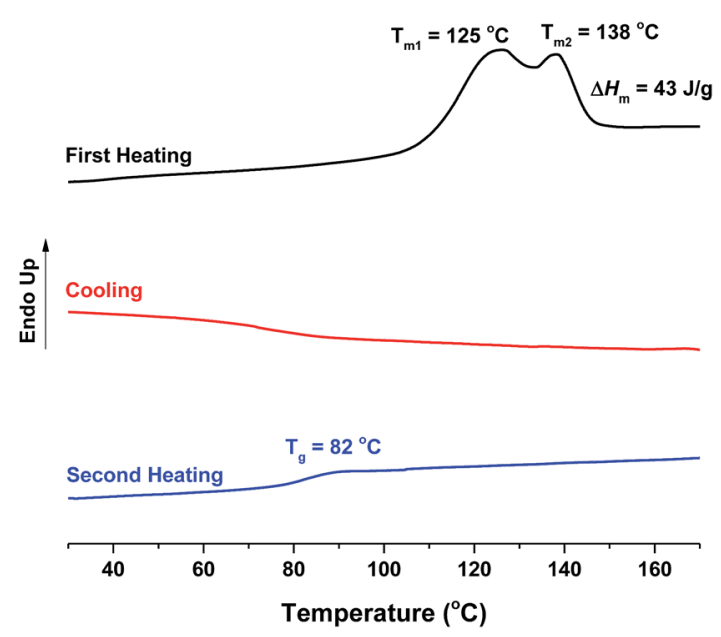

Fig. 11 DSC curves of the obtained PA12F. PA12F $\left(\overline{M_{\mathrm{n}}}=9500 \mathrm{~g} \mathrm{~mol}^{-1}\right.$, $\overline{M_{\mathrm{W}}}=19900 \mathrm{~g} \mathrm{~mol}^{-1}$ ) was produced via a one-stage enzymatic polymerization of DMFDCA and 1,12-DODA in toluene at $90^{\circ} \mathrm{C}$. 
(a)

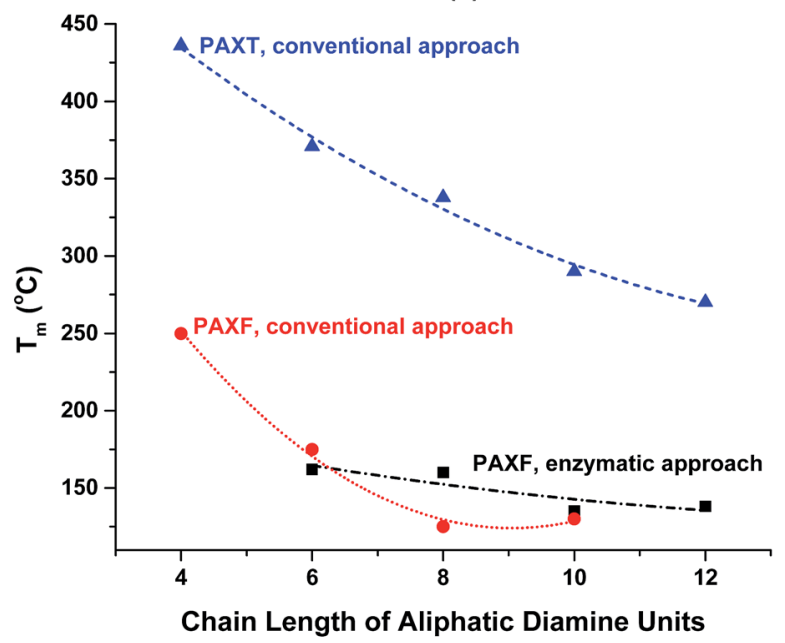

(b)

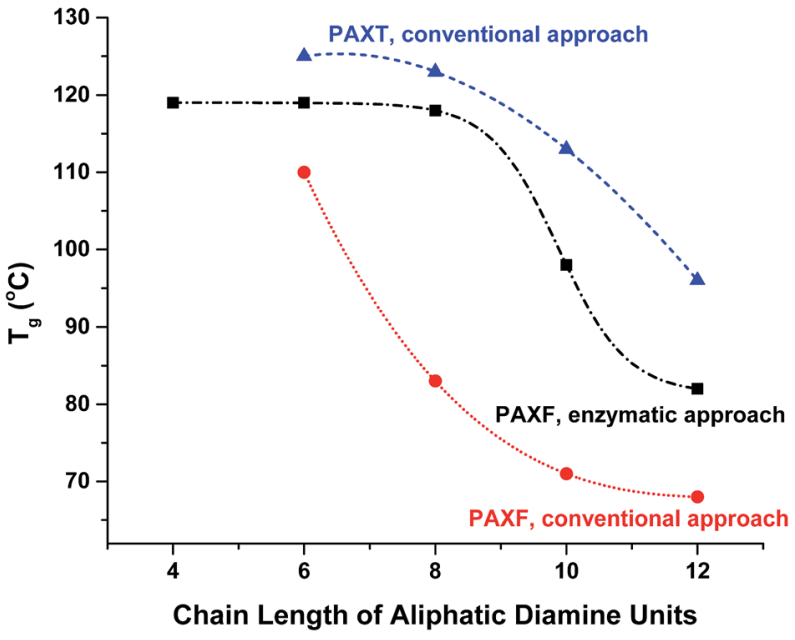

Fig. 12 (a) $T_{m}$, and (b) $T_{g}$ of the FDCA-based semi-aromatic polyamides (PAXF, $X$ represents the chain length of aliphatic diamine units) and TPA-based semi-aromatic polyamides (PAXT). The FDCA-based semi-aromatic polyamides were produced via enzymatic polymerizations in this study or by conventional synthesis techniques as reported in the literature, ${ }^{42-44}$ while the TPA-based semi-aromatic polyamides were synthesized via conventional approaches as reported in the literature ${ }^{49-52}$ If the polyamides possess several melting peaks or showed different $T_{m}$ in the literature, the highest $T_{m}$ is presented.

formation of defected polymer crystals in the FDCA-based semiaromatic polyamides and their lower degree of crystallinity, which is caused by the perturbed hydrogen bondings due to the additional interactions between amide groups and oxygen heteroatoms of furan rings. ${ }^{\mathbf{5 8}}$

\section{Conclusions}

A series of FDCA-based semi-aromatic polyamides is successfully synthesized via N435-catalyzed polycondensation of (potentially) biobased DMFDCA and aliphatic diamine differing in chain length (C4-C12), using a one-stage method at $90{ }^{\circ} \mathrm{C}$ in toluene. $\overline{M_{\mathrm{W}}}$ of the resulting products ranges from 15800 to $48300 \mathrm{~g} \mathrm{~mol}^{-1}$, which is higher than those produced via conventional synthesis techniques. We found that N435 shows the highest selectivity towards 1,8-ODA (C8) among the tested aliphatic diamines. Moreover, MALDI-ToF MS analysis suggested that no byproducts were produced, which could have indicated the occurrence of undesirable side-reactions during the enzymatic polymerization. Therefore, enzymatic catalysis is proven to be a robust pathway towards the synthesis of sustainable FDCA-based semi-aromatic polyamides. These FDCA-based semi-aromatic polyamides are promising biobased substitutes to petrol-based counterparts, which have a great commercial interest as thermal engineering plastics and high performance materials.

The enzymatic polymerization kinetics study suggested that $\overline{M_{\mathrm{w}}}$ increases significantly with increase of polymerization time. We also found that phase separation occurs in the early stage of polymerization, and the enzymatic solid-state polymerization takes place. However, a large proportion of the resulting polyamides possess low molecular weights. As a result, only less than $\sim 50 \%$ of the products were obtained after purification.

All obtained FDCA-based semi-aromatic polyamides possess a $T_{\mathrm{d}-5 \%}$ and $T_{\mathrm{d}-\mathrm{max}}$ at around $257-378$ and $443-466{ }^{\circ} \mathrm{C}$, respectively. In addition, these enzymatic polyamides display a $T_{\mathrm{m}}$ of around $125-162{ }^{\circ} \mathrm{C}$ (except PA4F), and a $T_{\mathrm{g}}$ of around $82-119{ }^{\circ} \mathrm{C}$. Moreover, the tested enzymatic FDCA-based semi-aromatic polyamides having longer diamine units generally possess a lower $T_{\mathrm{m}}$ and $T_{\mathrm{g}}$, but a higher crystallization ability.

The enzymatic FDCA-based semi-aromatic polyamides show a slightly higher $T_{\mathrm{m}}$ and $T_{\mathrm{g}}$, and similar thermal stability compared to those produced via conventional synthesis techniques. Furthermore, these enzymatic FDCA-based semiaromatic polyamides possess a comparable $T_{\mathrm{g}}$ and thermal stability, but a much lower $T_{\mathrm{m}}$ compared to the TPA-based counterparts.

Considering the fact that toluene is not an eco-friendly solvent, our future research will focus on the use of nonsolvent and green solvents such as ionic liquids and supercritical $\mathrm{CO}_{2}$ for the enzymatic polymerization of biobased polyamides. We also hope that the isolation yield and molecular weights can be improved by using such green solvents.

\section{Acknowledgements}

This research forms part of the research programme of the Dutch Polymer Institute (DPI), project \#727c polymers go even greener. The authors thank Masyitha Ambarwati for the photograph in the graphic table of contents. Dina Maniar thanks the financial support from the Indonesia Endowment Fund for Education (Lembaga Pengelola Dana Pendidikan/ LPDP).

\section{Notes and references}

1 R.-J. van Putten, J. C. van der Waal, E. de Jong, C. B. Rasrendra, H. J. Heeres and J. G. de Vries, Chem. Rev., 2013, 113, 1499-1597.

2 I. Delidovich, P. J. Hausoul, L. Deng, R. Pfutzenreuter, M. Rose and R. Palkovits, Chem. Rev., 2016, 116, 1540-1599. 
3 W. P. Dijkman, D. E. Groothuis and M. W. Fraaije, Angew. Chem., Int. Ed., 2014, 53, 6515-6518.

4 A. Scott, Chem. Eng. News, 2016, 94, 15.

5 E. D. Jong, M. A. Dam, L. Sipos and G. J. M. Gruter, in Biobased Monomers, Polymers, and Materials, American Chemical Society, 2012, vol. 1105, ch. 1, pp. 1-13.

6 P. F. H. Harmsen, M. M. Hackmann and H. L. Bos, Biofuels, Bioprod. Biorefin., 2014, 8, 306-324.

7 A. Gandini, T. M. Lacerda, A. J. Carvalho and E. Trovatti, Chem. Rev., 2016, 116, 1637-1669.

8 A. F. Sousa, C. Vilela, A. C. Fonseca, M. Matos, C. S. R. Freire, G.-J. M. Gruter, J. F. J. Coelho and A. J. D. Silvestre, Polym. Chem., 2015, 6, 5961-5983.

9 C. Vilela, A. F. Sousa, A. C. Fonseca, A. C. Serra, J. F. J. Coelho, C. S. R. Freire and A. J. D. Silvestre, Polym. Chem., 2014, 5, 3119-3141.

10 M. Trigo-López, P. Estévez, N. San-José, A. GómezValdemoro, F. C. García, F. Serna, J. L. Pena and J. M. García, Recent Pat. Mater. Sci., 2009, 2, 190-208.

11 J. M. García, F. C. García, F. Serna and J. L. de la Peña, Prog. Polym. Sci., 2010, 35, 623-686.

12 K. Marchildon, Macromol. React. Eng., 2011, 5, 22-54.

13 J. I. Iribarren, C. Alemán and J. Puiggalí, in Handbook of Engineering and Specialty Thermoplastics, John Wiley \& Sons, Inc., 2011, ch. 3, pp. 43-77, DOI: 10.1002/ 9781118229064.ch3.

14 S. Kobayashi, S. Shoda and H. Uyama, in Polymer Synthesis/ Polymer Engineering, Springer-Verlag, Berlin Heidelberg, 1995, vol. 121, pp. 1-30.

15 R. A. Gross, A. Kumar and B. Kalra, Chem. Rev., 2001, 101, 2097-2124.

16 S. Kobayashi, H. Uyama and S. Kimura, Chem. Rev., 2001, 101, 3793-3818.

17 S. Kobayashi and A. Makino, Chem. Rev., 2009, 109, 52885353.

18 R. A. Gross, M. Ganesh and W. Lu, Trends Biotechnol., 2010, 28, 435-443.

19 N. Miletić, K. Loos and R. A. Gross, in Biocatalysis in Polymer Chemistry, ed. K. Loos, Wiley-VCH Verlag GmbH \& Co. KGaA, Weinheim, Germany, 2010, ch. 4, pp. 83-129, DOI: 10.1002/ 9783527632534.ch4.

20 J. X. Zhang, H. Shi, D. Wu, Z. Xing, A. J. Zhang, Y. Yang and Q. S. Li, Process Biochem., 2014, 49, 797-806.

21 S. Shoda, H. Uyama, J. Kadokawa, S. Kimura and S. Kobayashi, Chem. Rev., 2016, 116, 2307-2413.

22 S. Kobayashi, Polym. Adv. Technol., 2015, 26, 677-686.

$23 \mathrm{~K}$. Loos, in Biocatalysis in Polymer Chemistry, ed. K. Loos, Wiley-VCH Verlag GmbH \& Co. KGaA, Weinheim, Germany, 2010, pp. 1-29.

24 A. Singh and D. L. Kaplan, in Enzyme-Catalyzed Synthesis of Polymers, ed. S. Kobayashi, H. Ritter and D. Kaplan, Springer-Verlag, Berlin Heidelberg, 2006, vol. 194, pp. 211224.

25 F. Hollmann, in Biocatalysis in Polymer Chemistry, ed. K. Loos, Wiley-VCH Verlag GmbH \& Co. KGaA, Weinheim, Germany, 2010, ch. 6, pp. 143-163, DOI: 10.1002/ 9783527632534.ch6.
$26 \mathrm{~J}$. van der Vlist and K. Loos, in Biocatalysis in Polymer Chemistry, ed. K. Loos, Wiley-VCH Verlag $\mathrm{GmbH} \&$ Co. KGaA, Weinheim, Germany, 2010, ch. 9, pp. 211-246, DOI: 10.1002/9783527632534.ch9.

27 E. Stavila and K. Loos, J. Renewable Mater., 2015, 3, 268-280.

28 G. G. Linares and A. Baldessari, Curr. Org. Chem., 2013, 17, 719-743.

29 H. N. Cheng, in Biocatalysis in Polymer Chemistry, ed. K. Loos, Wiley-VCH Verlag GmbH \& Co. KGaA, Weinheim, Germany, 2010, ch. 5, pp. 131-141, DOI: 10.1002/9783527632534.ch5.

30 E. Stavila, R. Z. Arsyi, D. M. Petrovic and K. Loos, Eur. Polym. J., 2013, 49, 834-842.

31 E. Stavila, G. O. R. Alberda van Ekenstein and K. Loos, Biomacromolecules, 2013, 14, 1600-1606.

32 K. Brandstadt, T. Lane and R. Gross, US Pat. US20070021578 A1, 2006.

33 G. Qu-Ming, W. W. Maslanka and H. N. Cheng, in Polymer Biocatalysis and Biomaterials II, American Chemical Society, Washington, DC, 2008, vol. 999, ch. 21, pp. 309-319.

34 L. Ragupathy, U. Ziener, R. Dyllick-Brenzinger, B. von Vacano and K. Landfester, J. Mol. Catal. B: Enzym., 2012, 76, 94-105.

35 F. Poulhès, D. Mouysset, G. Gil, M. P. Bertrand and S. Gastaldi, Polymer, 2013, 54, 3467-3471.

36 I. Baum, B. Elsässer, L. W. Schwab, K. Loos and G. Fels, ACS Catal., 2011, 1, 323-336.

37 Y. Poojari and S. J. Clarson, Macromolecules, 2010, 43, 46164622.

38 E. Stavila, G. O. R. Alberda van Ekenstein, A. J. J. Woortman and K. Loos, Biomacromolecules, 2014, 15, 234-241.

39 Y. Jiang, A. J. J. Woortman, G. O. R. Alberda van Ekenstein, D. M. Petrovic and K. Loos, Biomacromolecules, 2014, 15, 2482-2493.

40 Y. Jiang, A. J. J. Woortman, G. O. R. Alberda van Ekenstein and K. Loos, Polym. Chem., 2015, 6, 5198-5211.

41 Y. Jiang, D. Maniar, A. J. J. Woortman, G. O. R. Alberda van Ekenstein and K. Loos, Biomacromolecules, 2015, 16, 36743685 .

42 H. Hopff and A. Krieger, Makromol. Chem., 1961, 47, 93-113. 43 P. Heertjes and G. Kok, Delft Prog. Rep., Ser. A, 1974, 1, 59-63. 44 O. Grosshardt, U. Fehrenbacher, K. Kowollik, B. Tubke, N. Dingenouts and M. Wilhelm, Chem. Ing. Tech., 2009, 81, 1829-1835.

45 A. Duursma, R. Aberson, D. D. Smith, J. Flores, M. A. Dam and G. J. M. Gruter, International Patent WO 2015060718 A1, 2015.

46 D. D. Smith, J. Flores, R. Aberson, M. A. Dam, A. Duursma and G. J. M. Gruter, International Patent WO 2015059047 A1, 2015.

47 V. N. Tsarev, Y. Morioka, J. Caner, Q. Wang, R. Ushimaru, A. Kudo, H. Naka and S. Saito, Org. Lett., 2015, 17, 25302533.

48 H. Hopff and A. Krieger, Helv. Chim. Acta, 1961, 44, 10581063.

49 P. W. Morgan and S. L. Kwolek, Macromolecules, 1975, 8, 104-111. 
50 G. Zhang, Y. X. Zhou, Y. Li, X. J. Wang, S. R. Long and J. Yang, RSC Adv. , 2015, 5, 49958-49967.

51 G. Zhang, H. W. Yang, S. X. Zhang, Y. Zhang, X. J. Wang and J. Yang, J. Macromol. Sci., Part A: Pure Appl.Chem., 2012, 49, 414-423.

52 W. Z. Wang and Y. H. Zhang, eXPRESS Polym. Lett., 2009, 3, 470-476.

53 Y. Jiang, G. O. R. Alberda van Ekenstein, A. J. J. Woortman and K. Loos, Macromol. Chem. Phys., 2014, 215, 2185-2197.

54 Y. Jiang, A. J. J. Woortman, G. O. R. Alberda van Ekenstein and K. Loos, Biomolecules, 2013, 3, 461-480.
55 L. W. Ren, Y. S. Wang, J. Ge, D. N. Lu and Z. Liu, Macromol. Chem. Phys., 2015, 216, 636-640.

56 A. R. Katritzky, R. L. Parris, E. S. Ignatchenko, S. M. Allin and M. Siskin, J. Prakt. Chem./Chem.-Ztg., 1997, 339, 59-65.

$57 \mathrm{~J}$. Wu, P. Eduard, S. Thiyagarajan, L. Jasinska-Walc, A. Rozanski, C. F. Guerra, B. A. J. Noordover, J. van Haveren, D. S. van Es and C. E. Koning, Macromolecules, 2012, 45, 5069-5080.

58 C. H. R. M. Wilsens, Y. S. Deshmukh, B. A. J. Noordover and S. Rastogi, Macromolecules, 2014, 47, 6196-6206. 